\title{
Application of Class Shift in Translation from English to Chinese
}

\section{Fali MI}

\author{
Department of English \\ Shanghai Aurora College \\ Shanghai, China
}

\begin{abstract}
Translation from English to Chinese aimed to enhance students' comprehensive language skills is one of the most widely used teaching tasks applied to college English learning classroom. However, due to lack of theoretical studies and practical guidelines, students pay too much attention to formal equivalence in the light of English grammatical rules, thus resulting in some translated sentences with strong "translationese". Originated from translation transfer theory put forward by Catford, class shift is deeply rooted in Systemic Functional Linguistics depicting and analyzing two dimensions of level shift and category shift. The paper showcases how to translate English sentences into Chinese by relying on class shift with some classified and well sorted-out examples primarily taken from course books, attempts to render the deeper-level reasons behind the class shift, and tentatively makes analysis based on that. The paper exemplifies eight types of class shift in the process of translation from English to Chinese. Study shows that by relying on class shift, students focus more on functional equivalence rather than on formal equivalence and get rid of rigid scaffoldings involving in English grammar rules. As a result, "translationese" in the translated sentences can be effectively avoided and the target texts are more in the habit of Chinese way of expressions.

Key Words: class shift, formal equivalence, translationese
\end{abstract}

Cite as: MI, F. (2020 Application of Class Shift in Translation from English to Chinese. Arab World English Journal for Translation \& Literary Studies 4 (4) 213-224.

DOI: http://dx.doi.org/10.24093/awejtls/vol4no4.15 
Application of Class Shift in Translation from English to Chinese

\section{Introduction}

Languages, the deepest imprint and mark in the human mind, are the most cherished asset and creation by humans as a whole. Also, languages are the representative and characteristic of the human mind, from which our thinking evolves and develops, immerging human beings into the world around them.

English and Chinese are two different language systems. English is a kind of alphabetic writing belonging to the Indo-European language system while Chinese is hieroglyphics belonging to the Sino-Tibet language system. As spelling semiotics, hieroglyphics unconsciously shapes Chinese the way of thinking, which favors concreteness and meaning-based way of thinking. In contrast, influenced by abstractness and formality of alphabetic writing, Anglo-Saxon prefer logic and formality way of thinking. The differences of the two nationals in languages and thinking inevitably result in different ways of language expressions. Roughly speaking, the following three points feature the two languages of English and Chinese in terms of ways of expressions.

\section{1). English is hypotactic and Chinese is paratactic}

From the perspective of language family, English is a sub-branch of the Germanic Languages with the IndoEuropean Family as its forefather. Just as the other branches of the Indo-European Family, English is morphologically rich and called as an inflectional language. For example, roots or variations at the end of words distinguish categories or part of speech. There are deviations and forms for a verb of different tenses, to name just a few. In contrast, Chinese belongs to Sino-Tibet family without deviations or changes of forms. That is, it is non-inflectional.

In English, the relationship among words is often signified with a linking word, which is distinctive from Chinese where the relationship among words is generally rendered by readers. For instance, in the sentence " $I$ will stay at home if it rains", the relationship between two actions, namely stay and rain, is clearly signified and seldom will it produce any misunderstandings. To put it exactly the same as the above English does, Chinese relies on no linking word like “if” at all as in the sentence“下雨我就呆在家里”. It is natural for a native Chinese to render “下雨” as “if it rains", though literally “下雨“ means “it rains”, not "if it rains". In other words, we Chinese instinctively deem “下雨” is a conditional sentence, even if we don’t directly say “如果下雨”, literally if it rains. We take it for so granted that we stay at home on the condition if it rains that there is no need for us to say “如果下雨”, as we native Chinese all know intuitively and instinctively that “下雨”refers to “if it rains”, not "it rains in reality”. As Jia(2018, p.265) generalizes the differences of syntax of Chinese and English:

“......English is highly formalized and logical, rigid and complete in syntax structure with verbs as its core, putting emphasis on analysis while weighing less on abstract composition of meanings; Chinese does not attach importance of formality but depend so much on the order of written or spoken sentences. Verbs in Chinese do not play such a salient or prominent role as in English. Chinese stress on composition of meanings of words, neglecting analysis......"

To translate a hypotactic text into a paratactic one, the most commonly made error is to transfer the formcentered features of the former texts to the latter ones, which is meaning-centered.

\section{2). English is static and Chinese is dynamic}

Liu (2006, p.409) assumes that Chinese is a dynamic language while English tends to be static in essence. Another scholar, Mr. Lian Shuneng, equally holds the view that English tends to put in use more nouns, so the narrative style is of static characteristic while for Chinese, verbs are more exploited so the narrative style boasts dynamic feature.. To illustrate the static tendency of English in use, he points out some of the typical characteristics such as nominalization, nouns signifying agents, nouns replacing adjectives to construct theme phrases, advantages of nouns transferred to advantages of prepositions, weakness and vagueness of verbs,

Arab World English Journal for Translation \& Literary Studies 
adjectives and adverbials to express connotations of verbs etc.. Chinese is deemed to be dynamic for the fact that verbs are used on end, verbs and verb phrases function as various parts of speech and repetition of verbs (Lian, 2014, p. 104-p.127).

Eg.1. 闲言少叙, 却说宝玉因近日林黛玉回去, 剩得自己孤栖, 也不和人玩要, 每到晚间, 便索然睡 了。(曹雪芹, 2008, p171)

Yang's version: Let us return to Baoyu, who was so desolate after Daivu's departure that he had given up playing with his companions and went disconsolate to bed each night. (Yang \& Yang, 2003, p.335)

In Yang' version of translation, departure is used to replace the verb “回去”, literally "go back" or "depart", featuring typically the static language of English.

\section{3). English is process-oriented pragmatically and Chinese is outcome-oriented pragmatically}

Eg.2. (新华网) 岁末年初, 名目繁多的宴请活动开始增多, 由此造成的浪费也不可小觑。在蛇年春节 即将来临之际, 大力倡导节约理念, 狠刹浪费之风, 势在必行。(《遏制“舌尖上的浪费”》)

( BBC) It is a picture of publicly-funded gluttony and extravagance that a few months ago would have been very hard to glean from one so well connected. But something has changed and in China it is suddenly the political fashion to denounce the high-spending habits of the country's public servants. ("China turns against official extravagance")

The news clips above is the relevant Chinese government's report of policy aimed to address the issue of fighting against wasting at all levels. We have noticed that in reporting the news in Chinese, pragmatically verbs are more frequently used and there is a sense of motion rhythm in the sentences such as “在蛇年春节即将来临 之际, 大力倡导节约理念, 狠刹浪费之风, 势在必行”, where bold words are all verbs. On the contrary, in reporting the news in English, it is reported "it is suddenly the political fashion to denounce the high-spending habits", where only one verb, "denounce", is used to address the issue. From the report, we assume that in reporting the news in English, pragmatically abstract nouns and prepositions are more used and there is a strong sense of static cadence.

\section{The problems we are facing}

The book $21^{\text {st }}$ Century Practical English is a course series book published and released by Fudan University Publishing House targeting at the students in vocational colleges. With a large number of volumes released, a wide range of use across the country and long time span in service, the course book has been exerting great influence on students and teaching staff in vocational colleges in China. The course book is of four volumes with each volume containing 8 units or 16 texts all together. In the long process of serving as an instructor teaching $21^{\text {st }}$ Century Practical English, I find that the following problems bubble up to the surface when my students do the translation drills.

1). A large number of students take it for granted that learning English well is enough to do English to Chinese translation practice for the reason that Chinese is their mother togue which they are born to understand and grasp in a proficient manner and which, they regard as their advantage of doing English to Chinese translation practice. So much so that they spend a large amount of time learning English grammar, breaking long and complex sentences into several parts for analysis, and working out to find solutions to grammatical difficulties. By grasping English sentences semantically, they have no difficulty in translating them into Chinese, to the best understanding of their knowledge. They don't put emphasis on comparing ways of expression between English and Chinese so that a lot of illogical and illiterate translated Chinese version of sentences pop up, thus making them vague in meaning, inappropriate in structure and bizarre in discourse.

Arab World English Journal for Translation \& Literary Studies

ISSN: 2550-1542 | www.awej-tls.org 
Application of Class Shift in Translation from English to Chinese

2). Most of students are lacking in theoretical guidance. Even if they have heard of some translation theoretical terms such as "formal equivalence", "dynamic equivalence", "functional equivalence" or domestication, foreignization, they hardly understand what the terms really mean. They don't go through into deep understandings of the terms, not to mention the translation practice from English to Chinese under the guidance of the theories. As a result, quite a number of students are too loyal to, or too stick to the rules of English grammar when doing translation from English to Chinese, to do any changes or alterations to the code transfer as English grammar requires they should do it in English way. Besides, they are afraid of making any further moves for fear of making mistakes if they do, class shifts to say the least. Consequently, some Chinese version of translated sentences are of "tone of translation" or "translationese", weird and funny to read. In the long run, ecology of Chinese language has been challenged and ruined to some extent and spoiled in terms of its purity and completeness.

3). Even if some students are equipped with translation theories for guidance, it is still very hard to guide them to do translation from English to Chinese at the basic level of the languages such as grammar and vocabulary in an objective and practical way for the following reasons. On the one hand, some of the translation theories are too vague or abstract in expression to be understood fully or thoroughly so that in practice, it is a tough task to do the translation practice following them. In particular, some of the traditional Chinese translation theories such as "faithfulness", "expressiveness", "elegance", which are the most well-known theories for the Chinese translators, are too vague and abstract to follow because nobody knows how faithful it is before they can say they are doing translation from English to Chinese "faithfully". To some extent, the translation theories are to be understood in an intuitive and abrupt way, which relies heavily on individuals. For most of Chinese readers, it is acceptable to receive "more or less", "not too bad", or "understood in mind though not well structured in form" version of target text. Then translation practice comes back to the old way of analyzing English grammar and semantics of lexis etc.. On the other hand, English has been so prevalent and dominant in the current world that it is considered to be "piece of cake" or even fashionable to construct Chinese version of translation in an "English" way. Some of Chinese students show no or little respect for traditional way of grammatically-correct Chinese sentences.

We hold the view that difference of expression way in the process of translating English to Chinese must be taken into account to ensure the readability of target text. Applying class shift in the process is one way of achieving the goal. In fact, class shift is one of the basic ways in the process of translating English to Chinese. Code transfer is equal to the reconstruction of target text. There is no translation if there is no code transfer. Class shift is one of the ways of code transfer. By turning to class shift, a series of problems in the process of translating from English to Chinese could be resolved.

\section{Literature review}

Starting from the 1960s, with the development of science and technology, linguistics in particular, contemporary linguistic translation theories originated from the western countries are introduced and studied in China. Some western scholars such as Jacobson(1959),Katz \& Fodor(1963), Catford (1965), Halliday(1978), Newmark(1988) and Nida(1964) began to introduce their research in the field of linguistics to the studies of translation, resulting in the continuous development in the years to come and bringing the studies of translation to a new and unprecedent height.

As the founder of the "Prague" school of language, Jakobson for the first time put forward the concept of "translation equivalence", and came up with "differential equivalence" on the basis of asymmetric relations among different languages and difficulty of full equivalence of translation among different languages. Nida is one of the best known American translation practitioners and theorists. He specializes in linguistics so it is natural for him to evaluate the relationship between forms and functions from the perspective of linguistics. He 
elaborated on and theorized "functional equivalence" or "dynamic equivalence", which made immeasurable and insurmountable contribution to the contemporary research of western translation theories, exerting a more profound and far-reaching influence on the translation studies both at home and abroad. Represented figures in the Landon language school are Newmark and Catford, who study translation from the perspective of social attributes of linguistics, highlighting that the influence coming from the context of society on lexis, semantics and discourse must be taken into consideration while doing language translation, which is to say that social influence must play a part in choosing words of target text. Grounded on that concepts, Newmark put forward semantic-communicative theory model. Communicative translation combines domestication, literal translation and functional equivalence into one and tends to adopt translation practice of domestication or under-translation, so that source text and target text could reach equivalence of total communicative effect. In 1965, Catford published A Linguistic Theory of Translation, which is based on linguistics. In the book, he elaborates on his translation theory in a systematic fashion, exploring a new way of studying translation theory. Language translation, in essence, is the process of code transfer. For the very first time, Catford came up with the concept of "translation transfer" and defined the concept of shift, which took place in the process of translation, as "formal equivalence of source language into target language"(Shen Yuping,1999: p.281-p.286). According to Catford, there are mainly two types of shifts in the process of translation, i.e. level shifts and category shifts. As Catford's theory is deeply rooted in systemic functional language by Halliday, the concepts of "level" and "category" put forward by Catford are borrowed from Halliday's "scale and category grammar system", which contains the same concepts "level" and "category". In Catford's theory, language level refers to four levels of phoneme, morpheme, grammar and lexicon respectively while category level, refers to structure, class of words, unit and intra system. For phoneme and morpheme, it is very hard to make translation transfer from source language to target language. Hence, translation transfer which takes place in the language level merely occurs to grammar and vocabulary. Category shift means formal shift in translating source language into target language, including structure shifts, class shifts, unit shifts and intra system shifts. The main point under discussion is class shifts.

Here, the class shifts refer to the word class shifts in the process of translation, that is, class shifts take place when equivalence in the target language is not the same in word class as that in the source language. In translation practice, applying word class shifts are used most frequently and the widest in scope and the most commonly used way of doing translation practice. Talking about class shifts forms, nouns in the source language for instance, can be shifted into adjectives, verbs, prepositions in the target language and vice the verse. Based on the understanding of translators, shifted classes can be different accordingly. The following are two examples.

Eg.3. Neutrons act differently from protons. (English verbs can be shifted into Chinese nouns)

Chinese version: 中子的特性不同于质子。

Eg.4. We find difficulty in solving this problem. (English nouns can be shifted into Chinese adverbs or adjectives)

Chinese version: 我们觉得难于解决这个向题。

For English and Chinese, one represents phonetic and the other represents semantic. The most striking characteristic of Chinese grammar is covertness and the most prominent characteristic of English grammar is overtness. From the above two examples mentioned, in doing translation practice from English to Chinese, if we apply more class shifts, target language can be expressed in more clear, smooth and fluent manner and "translationese" can be effectively avoided and we are very safe to find theories to support us in applying class shifts when we do translation practice from English to Chinese.

\section{Significance of the study}

Arab World English Journal for Translation \& Literary Studies

ISSN: 2550-1542 | www.awej-tls.org 
Application of Class Shift in Translation from English to Chinese

Translation as a practice, has been going on for more than 2000 years both at home and abroad. During the long process of development in the west, different theories of translation equivalence have been put forward, either from the traditional linguistic approach, the semantic approach, the communicative approach or from the cultural approach. Foreignization vs. domestication, formal vs. functional, correspondence vs. adaptation, to name just a new, have been under discussion for so long that in the end an agreement is reached upon that no single approach suits translation practice once for all.

In China, chronically speaking, the translation theories have gone through the process of development of four stages, namely "script-fidelity-spiritual-resonance-faithfulness, expressiveness, elegance" (Luo Xinzhang, 1984; Xu Jun, Mu Lei, 2009). Or in other words, there are four key stages, which are "script, faithfulness, elegance, consummate transformation". Seng You (445-518) in the Nan Dynasty had his classical saying: "the excess of embellishment would be gaudy, while much stress on faithful description would be plain (文过则伤 艳, 质甚则患野). According to Lao Zi's saying “ the wording of embellishment is unfaithful, while the faithful wording ungraceful” (美言不信，信言不美), it is the same as the western understanding : “ the beautiful unfaithful one, the one unbeautiful ones". (Luo Xinzhang, 1984, p.22) Much more has been said on translation studies until now without even one minute of halt.

Whatever has been said on translation studies both at home and broad, it seems to be more of general principles or approaches involved in translation than of pragmatic methods or techniques to guide our students how to do it. Little had been said on translation studies about how to do it from linguistic point of view before Catford came up with his book A Linguistic Theory of Translation. Catford defined translation as " the replacement of textual material in one language (Source Language) by equivalent textual material in another language (Target Language)"(1965, p.20), and further claimed that " the central task of translation is that of defining the nature and conditions of translation equivalence" (1965, p.21), which can be procured at the levels of phoneme, lexis, phrase, syntax and discourse. And equivalence can be obtained at any possible level that is ranked hierarchically along the levels listed above.

The study is of importance because it offers pragmatic methods that students can learn how to do the translation from English to Chinese at the level of lexis, phrase to adapt target text to the habit of target readers. Also, it sheds light on the fact that in doing translation from English to Chinese, students are not so strictly bound to or confined to English grammatical rules in the cases where class shifts are needed. They are encouraged to pursue it without hesitation or fear that they are making mistakes for not following what grammar books require.

\section{Research questions}

RQ1: Is it acceptable to shift word class when doing translations from English to Chinese and what are the theories backing it up?

RQ1: If yes, how to do it?

\section{Primarily based on the course book $21^{\text {st }}$ Century Practical English, examples are showcased here to illuminate how to apply class shift in doing translation practice from English to Chinese.}

\section{1). English nouns are shifted to Chinese verbs}

A large number of studies on comparing English and Chinese clearly indicate that in Chinese, verbs are predominant and the Chinese sentences are more dynamic in syntax structure. Westerners however, are more likely to be static-minded, so they make more uses of nouns in constructing sentences and discourses, a phenomenon which we call obvious nominalization preference in language structure. In English lexis, nouns take up much more portion than verbs in number, which leads to semantic void of verbal expression in Chinese correspondence. In contrast, there are more verbs in Chinese language, so one verb in an English sentence needs several verbs or verbal expressions to do the job in Chinese equivalent sentence. In English, static nouns are

Arab World English Journal for Translation \& Literary Studies 
used to describe event process, behavioral phenomenon, emotional alteration and modal transfer etc., while verbs are more likely used in the cases in Chinese.

Of all the class shifts from English to Chinese, shifting English nouns to Chinese verbs is the most-applied technique we turn to when doing translation practice.

Eg.5. The loss of my job was responsible for some positive changes in my life. (B4, U1, short for $21^{\text {st }}$ Century Practical English, Book 4, Unit 1, marked as B4, U1.)

Chinese version: 失去工作使我的生活发生了一些积极的变化。

The word loss in the source text is the subject of the sentence to refer to a kind of event, denoting a static change of state. When translating it into Chinese, we put it into “我工作的失去” by simply following the principle "formal equivalence", that is to replace the English noun for a Chinese counterpart, then it is a rather awkward, weird and funny Chinese expression. It is a strong "translationese", which is illogical and inappropriate Chinese way. By applying class shift to transfer the English noun loss into a Chinese verb “失去”, the whole sentence is rendered in a smooth, concise and objective fashion, which is naturally habitual to the Chinese way of expressions.

Eg.6......, a downsizing initiative and a major bank merger resulted in the elimination of over one hundred jobs, ....... (B4, U5)

Chinese version: ......, 一次裁员行动和一次重大的银行合并导致了 100 多名员工被裁, ......

Elimination in the source text is an abstract noun describing changes of states and shifted into a verb "被 裁” when translated into Chinese, which is clarified and to the point in expression and in accordance with the expression characteristic of dynamic Chinese language.

Eg.7. Soon lives were being saved in emergencies by immediate injections of plasma. (B4, U7）

Chinese version: 不久, 一些急诊病人由于及时输入了血浆而获救。

Eg.8. Would deactivating the AI be considered murder? (B2, U2)

Chinese version: 卸除人工智能算是谋杀吗?

\section{2). English nouns shifted into Chinese adjectives}

Eg.9. My once secure future became a fallacy. (B4, U5)

Chinese Version: 我一度安全稳定的未来变得峎晨可危了。

Eg.10. The house was quiet. As quiet as death, thought Charlie Drew..... (B4, U7)

Chinese version: 屋子里一片寂静, 死一般的寂静， ......

The nominalization preference in English makes English nouns equipped with characteristics of verbs, adjectives and even adverbs, which also indicates that English nouns are cognitively condense and accurate with categorization. "To a large extent, English nouns are pretty much applied for the reason that abstract concepts are to be expressed, in other words, the abundance of English nouns are reflective of preference for abstract thinking by English nationals.” (Fu Jingmin, 2006)

\section{3). English prepositions (or prepositional phrases) shifted into Chinese verbs (or verbal phrases)}

Arab World English Journal for Translation \& Literary Studies

ISSN: 2550-1542 | www.awej-tls.org 
English prepositions are used with high frequency and with flexible meanings, possessing semantic characteristic of dynamic image schema and formal space hypothesis. Image schema are grounded primarily on space relation, for instance, IN-OUT schema、UP-DOWN schema、FRONT-BACK schema etc., and extended to other cognitive domain through metaphor, to name just one. (Wang Yin 2007:192) For example, the preposition over possesses characteristic of Source-Path-Destination Schema. While in Chinese, most prepositions are grammaticalized from verbs (Huang Borong,1081,p.313). Hence, when doing translation practice from English to Chinese, the connotational image schema of English prepositions are generally required to be turned into corresponding Chinese verbs. It is pretty common to shift English prepositions into Chinese verbs when doing translation practice.

Eg.11. "Coming!” Away she skimmed over the lawn, up the path, up the steps, across the veranda, and into the porch.

Chinese version: “来了! ”她转身蹦着跳着跑了, 越过草地, 跑上小径, 跨上台阶, 穿过凉台, 进了门 廊。

Eg.12. It has been called "a poem in marble" and is said to be the most expensive compliment ever paid to a woman. (B4, U8)

Chinese version: 它被成为“用大理石写成的诗“, 并据称是对一个女人最为昂贵的赞美。

Eg.13. "With the help of God you will live to be a hundred and twenty," said my mother. (B4, U1 ) Chinese version: “有上帝的佑护, 你会活到120岁的, ”我母亲说。

Eg.14. They disciplined me at home but also remained vigilant in their support of me, constantly looking for ways to help me move forward. (B3, U3)

Chinese version: 他们在家里对我严加管教, 但又时时不忘给我支持, 并一直寻求办法帮助我前进。

Eg.15. While I didn't become an angel overnight, with my parents-support and a new school, I got on the right track and developed the self-confidence I desperately needed. (B3, U3)

Chinese version: 尽管我没有在一夜之间变成天使, 然而有了父母的支持和一个新的学 习环境, 我还 是走上了正轨,并树立起我极需的自信。

Eg.16. He is a man above vulgar interests.

Chinese version: 他是个脱离了低级趣味的人。

Eg.17. I am against it.

Chinese version: 我反对（这件事）。

Eg.18. Time Warner will pay TCI 360 million for Southern Satellite company.

Chinese version: 时代华纳愿付给 TCI三亿六千万美元购买南方卫星这家公司。

\section{4). English adjectives shifted into Chinese nouns}

Eg.19. What's so mvsterious about the English language? (B2, U1)

Chinese version: 英语有何奥秘之处?

Eg.20. She had been old, sick, and desperate. (B2, U3)

Chinese version: 而她却年老多病, 身处绝境。

Arab World English Journal for Translation \& Literary Studies

ISSN: 2550-1542 | www.awej-tls.org 
It is worthy of our attention that English adjectives, when functioned as predicative, are shifted into Chinese nouns, the shifted nouns are added at the end with “-度”、“-性”、“-体” as the English adjectives generally have the connotation with characteristic of things. For example:

Eg.21. This workpiece is not more elastic than that one.

Chinese version: 这两个工件都没有弹性。

\section{5). English verbs shifted into Chinese nouns}

Eg.22. Here I was surrounded by people I did not know and who did not know me.（B1, U1）

Chinese version: 在这里, 四周都是我不认识的人, 而他们也不认识我。

In this sentence, if surrounded is translated into Chinses according to the word class as a verb, then the translated Chinese syntax structure will be in passive form, which is quite awkward in Chinese. After the verb surrounded is shifted into a Chinese noun, then the whole sentence is rather smooth, clear and quite in the habit of Chinese expressive way.

Eg.23. I would very much appreciate it if you could take our suggestion into consideration. Chinese version: 希望你们考虑一下我们的意见。

Eg.24. The new contract will expire in 5 years.

Chinese version: 新合同的有效期为 5 年。

\section{6). English adjectives shifted into verbs}

English adjectives indicating psychological states such as consciousness, desires, or emotions etc., when functioned as predicative, are usually shifted into the corresponding Chinese verbs. The following are the kind of adjectives: able, afraid, angry, ashamed, aware, anxious, careful, cautious, certain, concerned, confident, doubtful, glad, grateful, ignorant, sorry, thankful etc..

Eg.25. Many Americans are familiar with The Little Prince, a wonderful book by Antoine de Saint-Exupery. (B1, U7)

Chinese version: 很多美国人都熟悉安托万·德·圣埃克苏佩里写的那本精彩的书《小王子》。

Eg.26. From the contemptuous looks and rough treatment he received from his jailers, he was sure that he would be executed the next day. (B1, U7)

Chinese version: 从狱卒们轻䓏的脸色和他受到的粗暴对待判断, 他确信第二天他就会 被处决。

Eg.27. Please let me know if our terms are acceptable.

Chinese version: 请告知是否接受我方条款。

\section{7). English adverbs shifted into Chinese adjectives}

Eg.28. Security laws require companies to treat all shareholders reasonablv equally.

Chinese version：证券法要求公司给所有持股人既合理又平等的待遇。

The two adverbs in the sentence, reasonably and equally, are translated into adjectives, which is rather rational and equal. At the same time, the verb treat is correspondingly translated into the noun “待遇”. In this way, the meaning of the source text are preserved, truly achieving the goal of "being faithful" and "being 
Application of Class Shift in Translation from English to Chinese

expressive".

\section{8). English verbs shifted Chinese nouns}

Eg.29. A well-dressed man, who looked and talked like an American, got into the car. Chinese version: 一个穿着讲究的人上了车。他的外表和谈吐都像个美国人。

The two verbs looked and talked in the original text are translated into two nouns, which is concise, clear, simplified and worthy of applause.

\section{Discussion}

For the sake of students learning $21^{\text {st }}$ Century Practical English, most of the examples illustrated here in the paper are taken from the series book. Confined to the selected range of samples, sometimes it is a hard task to choose the best appropriate and the most suitable examples to explain and to illustrate what we are talking about in the paper and so, it is the same equally tough task to explain the theory of class shifts with the most sufficient, the most detailed and multi-faceted examples.

Catford's translation transfer theory takes advantage of and deeply rooted in linguistics and Catford puts forward level transfer and category transfer. In the theory, he concretely and in a detailed manner elaborates on the two different types of level transfer and category transfer, which defines and outlines clearly the scope and the range of translation transfer used from the perspective of all branches of linguistics, without considering the influence of concerned culture, psychology and sociology etc. on code transfer happening in the process of translation, hence it is beyond reach to explain all the transfers accompanied with the translation process.

Since there is big difference of way of expression between English and Chinese, it is equally important to showcase how to apply class transfer when doing translation practice from Chinese to English. So, it seems better to explain the translation theory of class shifts in the process of doing translation in mutual way, i.e. from English to Chinese and from Chinese to English.

\section{Further research}

The paper showcases Catford' translation transfer theory with concrete examples taken from the course book widely used at colleges in China, mainly focusing on how class shifts happen in code transfer from source language to target language. For the rest of his theory which incorporates transfer at the level of grammar and vocabulary as well as structure shifts, unit shifts, intra system shifts at the level of category, it is not illustrated in the paper, leaving much place in the future to fill in so as to bring more renderings to the course book $21^{s t}$ Century Practical English from more different angles to benefit both the teachers and students using the book.

In the process of class shifts, a certain kind of words, adjectives with certain kind of semantic property for instance, is more likely to carry out class transfer when doing translation practice. A case in point is that the English adjectives with abstract meanings describing characteristics of things are more likely to be shifted into the corresponding Chinese nouns while other general adjectives seldom do, which requires further explanations and rendition from the perspective of semantics and cognitive linguistics.

Meaning is reconstructed in the process of class shifts. However, categories of adjectives are different from that of the shifted nouns in meaning. So, the adjectives and the shifted nouns with more or less the same semantics are not likely to convey fully identical message. According to Prof. Langacker, one of the leading cognitive linguists in the world, he assumes that the lexical category like nouns, verbs, adjectives, adverbs etc. is not only associated with grammatical message of formal category, but also associated with meaning itself. For example,

Eg.30. The loss of my job.

Arab World English Journal for Translation \& Literary Studies

ISSN: 2550-1542 | www.awej-tls.org 
Application of Class Shift in Translation from English to Chinese

I lost my job.

Though the above two sentences (phrases)mentioned are identical in expressing syntax semantics, the noun loss in the first sentence and the verb lost in the second one are different in the degree of metaphor and that is the reason why the above two sentences (phrases)mentioned do not convey fully identical message, as opposed to what many readers think. Consequently, special attention should be given to it in the process of class shifts when doing translation practice and further research on it is to be needed in future.

\title{
9. Conclusion
}

Researches on Catford's theories in China has been largely restricted to his equivalence translation while much more attention is still needed to be placed on his theory of class shift. In fact, Catford's theory of translation transfer aims more directly to guiding translation practice and translation teaching. There are several reasons which can account for it. For one thing, Catford elaborately and systematically classifies transfer phenomenon in the process of translation based on the theory of general linguistics, from which Chinese traditional translation practice and approach can learn quite a lot since it is primarily centered on vague, ambiguous, experienceoriented and impression-focused caliber. So much can be learned in such greater details and then applied to practical translation from Catford's theory that students are not at a loss and put into chaos. For another, in teaching translation from English to Chinese, Catford's transfer theory is conducive to students' understanding of difference between native language and second language in form and structure, thus reducing risks of negative transfer from native language to foreign language and as a consequence greatly eliminating the phenomenon of translationese.

Looking at translation theories and strategies at home and abroad, little has anyone, like Catford, ever strived to carry out translation study in such a systematical and detailed manner starting from basic language level. Catford described all language levels of target text in a scientific and meticulous way in terms of level and category, which placed so much influence on guiding translation teaching and practice for both undergraduate schools and college schools.

The paper summarizes eight different types of word class shifts happening in the process of translation from English to Chinese, which concerns reciprocal shifts of different word classes including nouns, verbs(verbal phrases), adjectives, adverbs, prepositions (prepositional phrases) etc.. As revealed clearly from the illustrations, the translated sentences after class shifts are smooth in sentential meanings, coherent in sentential structure and in accordance with Chinese traditional expression way of sentential structure. As a result, after the word classes are shifted accordingly, functional or intentional equivalence between source text and target text is reached. The students at the college level in China are generally not only low in English proficiency but also they are at a disadvantageous position in expressing themselves in Chinese. In doing translation practice from English to Chinese, after they are taught how to make class shifts, they are not confined to or entangles with the English grammatical rules and consequently, they can apply word class shifts to their translation practice boldly and consciously. In the end, they feel so at ease and at freedom that they won't be coward and conservative in doing translation and their proficiency of translation from English to Chinese are greatly enhanced and upgraded to a higher level.

\begin{abstract}
About the author:
Fali MI, is an instructor in Aurora College. He received his Master of English Language and Literature degree from Shanghai International Studies University. He was a visiting scholar in Fudan University in 2012. His main research interests include translation studies, cognitive linguistics and second language acquisition.
\end{abstract} ORCiD ID; https://orcid.org/0000-0002-4912-5459

Arab World English Journal for Translation \& Literary Studies

ISSN: 2550-1542 | www.awej-tls.org 


\section{References:}

Fu, J.M. (2018), Thorns of Translation Studies. Shanghai: Fudan University Press

Jia, Y.X.(1997). Intercultural Communication, Shanghai: Shanghai Foreign Language Education Press.

Jiang, Q.X. (2007). Thought on the Paradigm of Translation Transfer-Discussion on the Translation Discipline Properties. Journal of Chinese Foreign Languages, 4,(11),84-88

Lian, S.N. (1993). Contrastive Studies of English and Chinese, Beijing: High Education Press.

Lin, L. (2009). Study of the Translation Process in the Mode of Catford's Translation Transfer. Journal of Translation Studies, (5), 74-75

Long, Y.L. (2019). The Application of Translation Transfer Theory in Mutual Translation Between Islamic and Chinese. Journal of Contemporary Education Practice and Teaching Research, 1,(7), 192-221

Mu, L. (1990). Comments On Catford's A Linguistic Theory of Translation. Foreign Language Teaching, 11, (2),38-42

Peng, C.J. (2017). Study on Grammatical Category and Semantic Property of Verbs and Non-verbs in the Mutual Translation Between English and Chinese-Discussion with Mr. Lian Shuneng, Journal of Foreign Language and Translation, 93, (2), 39-45.

Sun, J. etc.(2014).Class Shifts of English to Chinese Translation in Agricultural Papers. Journal of Chinese Science Translation, 27, (4), 4-6.

Tong, P.S. (2011). Equivalence in the Western and the Chinese History of Translation: Disputes and a Solution. Kunming: Yunnan University Press.

Wan, H. (2017). Approximation-A Study on Chinese Idiom Translation. Shanghai: Shanghai University Press.

Wang, H. (2007). Cognitive Linguistics. Shanghai: Shanghai Foreign Language Education Press.

Wang, J.G. \& He, Z.R. (2014). Emphasis on Process or on Result. Journal of Shanghai Translation, (2),7-12.

Wang, L. (2006). Construction Type of Transformation of English Lexis and Translation Approach of Lexis Transformation in English-Chinese Translation. Journal of Shanghai Translation ,(3), 24-27.

Wen, Y.C. (2013). English Nouns Advantages and Mutual Translation Between English and Chinese. Journal of Foreign Philology, (6), 150-153.

Ye, Z.N. (2017). Second Thought on Class Shifts in Translation. Journal of Chinese Translation, (6), 32-33.

Ye, Z.N. (2001). Advanced Course in English-Chinese Translation (Third Edition). Beijing: Tsinghua University.

Zhang, P.J. (2009). A Course in English - Chinese Translation. Shanghai: Shanghai Foreign Language Education Press.

Zheng, S.M.\& Cao, H. (2011). The Application of Catford's Translation Transfer Theory in Chinese Translation from Scientific English. Journal of Chinese Science Translation,24,(11), 17-20. 